\title{
CESMI(WACCM) STRATOSPHERIC AEROSOL GEOENGINEERING LARGE ENSEMBLE PROJECT
}

Simone Tilmes, Jadwiga H. Richter, Ben Kravitz, Douglas G. MacMartin, Michael J. Mills, isla R. Simpson, Anne S. Glanville, John T. Fasullo, Adam S. Phillips, Jean-Francois lamarque, Joseph Tribia, Jim Edwards, Sheri Mickelson, and Siddhartha Ghosh

\author{
An overview is presented of the GLENS project, a community-wide effort enabling \\ analyses of global and regional changes from stratospheric aerosol geoengineering \\ in the presence of internal climate variability.
}

$\int$

olar geoengineering using stratospheric sulfate aerosols has been discussed as a potential means of deliberately offsetting some of the effects of climate change (Crutzen 2006). Various model studies have demonstrated that reducing incoming solar radiation globally can offset the increase in global average surface temperature associated with increasing greenhouse gases (e.g., Kravitz et al. 2013). Despite the stabilization of global surface temperature, these simulations show significant changes in atmospheric conditions with global solar reductions or stratospheric sulfur or aerosol injections. Side effects in these simulations include "overcooling" of the tropics and "undercooling" of the poles, leading to continued Arctic summer sea ice loss (e.g., Moore et al. 2014; Tilmes et al. 2016). Additionally, the slowing of the hydrological cycle (e.g., Schmidt et al. 2012) and the potentially uneven cooling between the two hemispheres resulting from solar geoengineering can lead to shifts in precipitation patterns (Haywood et al. 2013; Jones et al. 2017) and reductions in monsoon precipitation (Tilmes et al. 2013). Many available model results to date are based on an artificial design intended to explore the impact of large forcing effects through global solar dimming. For other experiments, only a few ensemble members are performed, making it difficult to identify the robustness of regional climate effects.

Simulations of stratospheric sulfate aerosol geoengineering inject sulfur dioxide $\left(\mathrm{SO}_{2}\right)$ into the stratosphere that oxidizes to form sulfate aerosols or they use direct injections of sulfate aerosols. These experiments require model capabilities beyond those in solar reduction simulations. The stratospheric aerosol distribution resulting from such injections depends on the model's aerosol microphysical scheme, as well as interactions with chemical, dynamical, and radiative processes (Pitari et al. 2014; Mills et al. 2017). Aerosol size and sedimentation are increased with the injection amount and the efficiency of the sulfates to affect the top of the atmosphere radiative imbalance is reduced (Niemeier and Timmreck 2015; Kravitz et al. 2017; Kleinschmitt et al. 2017). The warming of the tropical stratosphere in response to the enhanced aerosol burden results in circulation changes in the stratosphere with potential effects 
on the quasi-biennial oscillation (QBO; Aquila et al. 2014), as well as impacts on the tropospheric circulation (Richter et al. 2018). Changes in the chemical composition, including changes in water vapor and ozone, as well as changes in tropospheric clouds, may alter the long- and shortwave climate forcing. All these factors add complexity and potential sources of nonlinearity to the model response, leading to increased uncertainty in the results. Furthermore, shortcomings in our current knowledge of climate system interactions and future climate forcings makes it practically impossible to precisely predict the required injection regimes with a substantial lead time, in order to meet specified climate objectives.

ADVANCES OF THIS PROJECT. In this project, we combine four key elements aimed at meeting specific climate goals in order to advance our understanding of the impacts of stratospheric aerosol geoengineering and to overcome some of the abovementioned limitations by using a strategic approach.

i) We employ the state-of-the-art Community Earth System Model, version 1, using the Whole Atmosphere Community Climate Model [CESM1(WACCM)] as its atmospheric component, which provides a comprehensive representation of atmospheric conditions in both the

AfFiliations: Tilmes AND Mills-Atmospheric Chemistry, Observations, and Modeling Laboratory, National Center for Atmospheric Research, Boulder, Colorado and Atmospheric Chemistry, Observations, and Modeling Laboratory, National Center for Atmospheric Research, Boulder, Colorado; RICHTER, Simpson, Glanville, Fasullo, Phillips, Lamarque, Tribia, and EDWARDS-Climate and Global Dynamics Laboratory, National Center for Atmospheric Research, Boulder, Colorado; KravitZ-Atmospheric Sciences and Global Change Division, Pacific Northwest National Laboratory, Richland, Washington; MACMARTIN-Mechanical and Aerospace Engineering, Cornell University, Ithaca, New York, and Department of Computing and Mathematical Sciences, California Institute of Technology, Pasadena, California; Mickelson AND GHOSH-Computational Information Systems Laboratory, National Center for Atmospheric Research, Boulder, Colorado

CORRESPONDING AUTHOR: Simone Tilmes, tilmes@ucar.edu

The abstract for this article can be found in this issue, following the table of contents.

DOI:10.1175/BAMS-D-17-0267.I

In final form I May 2018

(C)2018 American Meteorological Society

For information regarding reuse of this content and general copyright

information, consult the AMS Copyright Policy. troposphere and stratosphere (Mills et al. 2017), and is coupled to land, sea ice, and the ocean.

ii) We inject $\mathrm{SO}_{2}$ at four predefined injection locations at $\sim 5 \mathrm{~km}$ above the tropopause, namely at $30^{\circ} \mathrm{N}$, $30^{\circ} \mathrm{S}, 15^{\circ} \mathrm{N}$, and $15^{\circ} \mathrm{S}$, that are sufficient to modify the stratospheric aerosol distribution in order to maintain the global mean surface temperature T0, the interhemispheric (positive northward) temperature gradient $\mathrm{T} 1$, and the equator-to-pole (projection onto quadratic) temperature gradient T2, as defined by Kravitz et al. (2017).

iii) We use a feedback-control algorithm coupled to CESM1(WACCM) that annually adjusts the amount of sulfur injection at each of the four locations, based on departures of the simulation from chosen objectives from the previous years.

iv) We employ a 20 -member geoengineering large ensemble [the Stratospheric Aerosol Geoengineering Large Ensemble (GLENS)], which was the amount possible with the available computer resources, to enable a more robust assessment of the regional climate response within the variability of the climate system.

As is now well recognized within the context of detecting climate change signals, assessment of the statistical significance and robustness of regional changes, as well as an appreciation of the possible futures that could arise as a result of the combined influence of climate forcings and internal variability, can benefit greatly from the use of multimember ensembles (Kay et al. 2015).

THE MODEL. All simulations are performed with the state-of-the-art CESM (Hurrell et al. 2013). Different model components, as listed in Table 1 , are interactively coupled. The atmospheric model, WACCM, uses a $0.9^{\circ}$ latitude $\times 1.25^{\circ}$ longitude grid with 70 vertical layers reaching up to $140 \mathrm{~km}\left(\sim 10^{-6} \mathrm{hPa}\right)$. The model includes comprehensive, fully interactive middle atmosphere chemistry with 95 solution species, two invariant species, 91 photolysis reactions, and 207 other reactions. The chemical scheme includes gas-phase and heterogeneous reactions important for stratospheric ozone chemistry, as well as sulfur-bearing gases important for stratospheric sulfate formation (Mills et al. 2017). A simplified chemistry scheme is used in the troposphere, which supports the formation of aerosols and is coupled to interactive biogenic emissions from the land model (Table 1). As a result, the simulations presented here are not suitable for investigating changes in tropospheric ozone or other tropospheric trace gases. This model has been updated with the capability to simulate the 
TABLE I. CESM(WACCM) components used for GLENS; see text for more details.

\begin{tabular}{|lll|}
\hline Model component & Version & Reference \\
\hline Atmosphere & WACCM & Marsh et al. (20I3), Mills et al. (20I7) \\
\hline Aerosol & MAM3 & Liu et al. (20I2) \\
\hline Land & CLM4.5 & Oelson et al. (20I7) \\
\hline Biogenic emissions & $\begin{array}{l}\text { Model of Emissions of Gases and Aerosols } \\
\text { from Nature version 2.I (MEGAN2.I) }\end{array}$ & Guenther et al. (20I2) \\
\hline Sea ice & Los Alamos Sea Ice Model (CICE4) & Holland (20I3) \\
\hline Ocean & Parallel Ocean Program (POP2) & Danabasoglu et al. (20I2) \\
\hline
\end{tabular}

TABLE 2. Summary of available model simulations used in this project. Detailed case names and initialization file names are provided to document file names for potential users of the model output, whereby $X X$ in column 3 refers to member numbers.

\begin{tabular}{|lccc|}
\hline Simulation & Years & Case & Ensemble members \\
\hline RCP8.5 & $2010-97$ & $\begin{array}{c}\text { b.el5.B5505C5WCCML45BGCR.f09 gl6. } \\
\text { control.0XX }\end{array}$ & $3(001-003)$ \\
\hline RCP8.5 & $2010-30$ & b.el5.B5505C5WCCML45BGCR.f09 gl6. & control.0XX \\
\hline Geoengineering & $2020-99$ & b.el5.B5505C5WCCML45BGCR.f09 gl6. & (004-020) \\
\hline
\end{tabular}

formation of stratospheric sulfate aerosols after the injection of $\mathrm{SO}_{2}$, through oxidation with interactively changing $\mathrm{OH}$, using a modal aerosol model [the three-mode version of the Modal Aerosol Module (MAM3)], which is interactively coupled to chemistry and radiation (Mills et al. 2016). MAM3 includes comprehensive aerosol microphysics to simulate required processes including nucleation, coagulation, condensational growth, evaporation, and sedimentation and is applied in both the troposphere and stratosphere. The coupling between tropospheric aerosols, clouds, and radiation is resolved and described by Liu et al. (2012). For this project, we use a new version of the land model [Community Land Model, version 4.5 (CLM4.5) instead of CLM4.0]. Compared to the earlier version, CLM4.5 includes an active terrestrial carbon cycle, including photosynthesis and respiration, considering different carbon and nitrogen pools. Some significant changes in the climate response are identified when using the updated CLM4.5 compared to CLM4.0, including seasonal changes in surface temperatures over the Arctic. A detailed evaluation of the model (using CLM4.0) is provided by Mills et al. (2017).

The model compares favorably with present-day observations in terms of its climatology and the variability of the ocean and atmosphere. It produces a reasonably good representation of the QBO and an excellent representation of stratospheric ozone column and water vapor concentrations (Mills et al. 2017). Furthermore, this model compares very well with observations of radiative forcing changes when simulating the period following the 1991 eruption of Mount Pinatubo (Mills et al. 2017) and is therefore well suited to perform stratospheric aerosol geoengineering experiments.

SIMULATIONS. The GLENS simulations use prescribed greenhouse gas forcing concentrations following the representative concentration pathway 8.5 (RCP8.5; i.e., a high anthropogenic emission scenario). This setup requires steadily increasing sulfur injections for the geoengineering simulations to counteract the forcing of increasing greenhouse gases in order to keep the climate at 2020 conditions. The purpose of this setup is not to suggest a realistic application, but to identify the side effects, risks, and limitations of geoengineering, while applying increasing sulfur injection rates in a single model. Details about the setup of the simulations (including case names) are listed in Table 2. The evolution of global mean surface temperature $\mathrm{T} 0$, interhemispheric surface temperature gradient $\mathrm{T} 1$, and equator-to-pole surface temperature gradient $\mathrm{T} 2$ are shown in Fig. 1.

The RCP8.5 simulations are started in 2010 using atmospheric initial conditions from a CESM1(WACCM) free-running historical simulation, following the RCP8.5 emission scenario (after 2005), as described by Mills et al. (2017). Initial conditions for the land and river model are taken from a $10-y r$ spinup simulation 
with CESM1(WACCM), branched from a transient historical (1850-2010) CESM1 simulation coupled to the CLM4.5 land model. The 20-member ensemble starts in 2010 and continues until 2030. Three ensemble members are extended at least until 2097, with only one (ensemble number three) completing year 2099 because of instabilities in simulating RCP8.5 toward the end of the twenty-first century. For each ensemble member, the atmospheric state is initialized with 1 January conditions taken from different years between 2008 and 2012 of the reference simulation and a round-off (order of $10^{-14} \mathrm{~K}$ ) air temperature perturbation, while the land, sea ice, and ocean start from the same initial conditions for each ensemble member. The ocean and sea ice initial conditions were taken from year 2010 of member 001 of the CESM Large Ensemble Project (Kay et al. 2015). This approach provides a reasonable sampling of atmospheric internal variability but does undersample the potential contribution of ocean states.
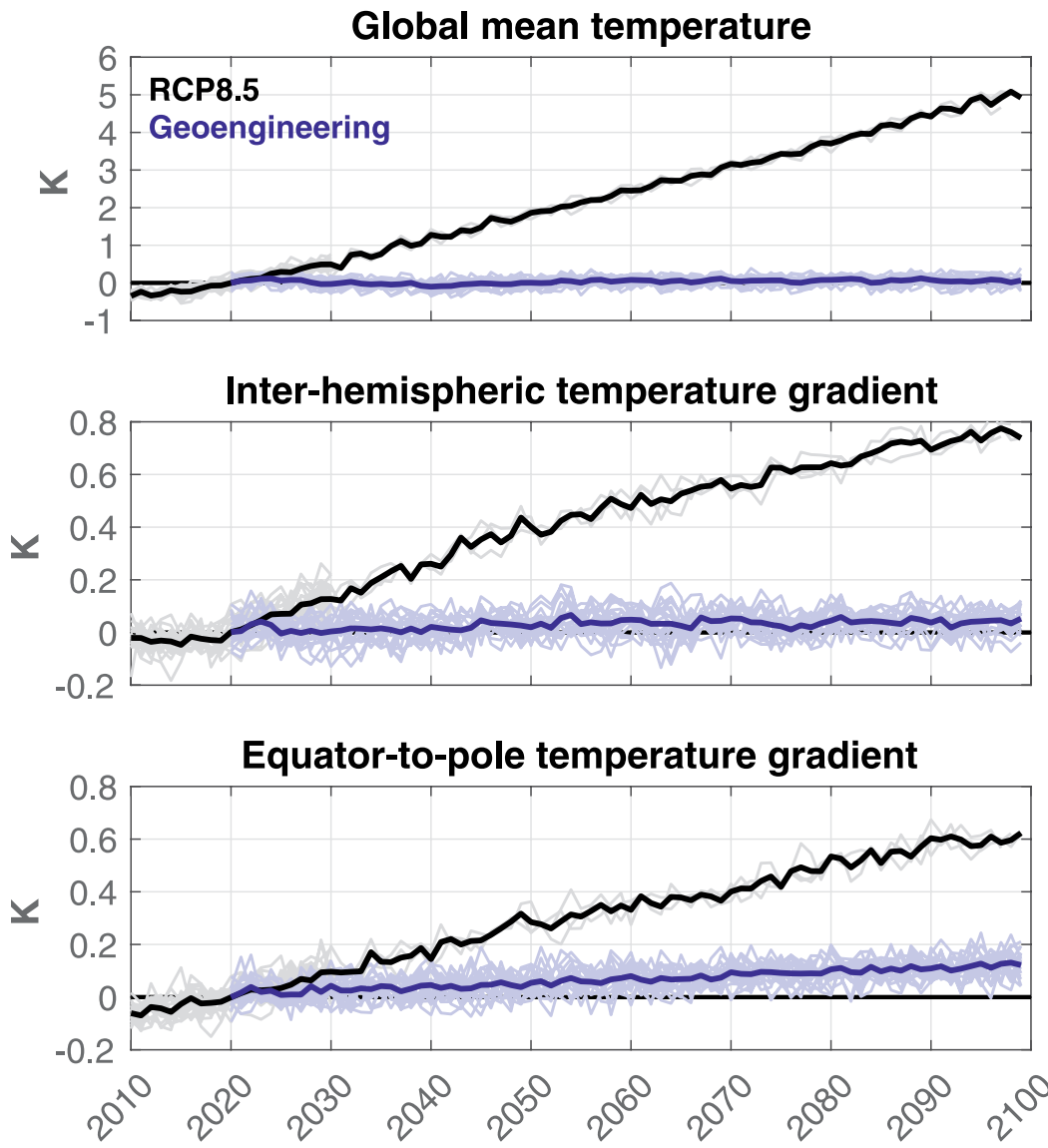

FIG. I. (top) Global mean surface temperature T0, (middle) the interhemispheric surface temperature gradient $\mathrm{TI}$, and (bottom) the equator-to-pole surface temperature gradient T2 for RCP8.5 (gray for single ensemble members and black for the ensemble mean) and for the geoengineering simulations (light blue for single ensemble members and dark blue for the ensemble mean) as compared to 2015-25 values of the RCP8.5 simulation.
The geoengineering simulations are set up the same way as the RCP8.5 simulations, but using injections of $\mathrm{SO}_{2}$ at four independent locations $\left(15^{\circ} \mathrm{N}\right.$ and $15^{\circ} \mathrm{S}$ at $25 \mathrm{~km}$ and $30^{\circ} \mathrm{N}$ and $30^{\circ} \mathrm{S}$ at $22.8 \mathrm{~km}$, all at an arbitrarily chosen longitude of $180^{\circ}$ ) with the goal of keeping the climate conditions representative of 2020 (Fig. 1).

Temperature targets for 2020 conditions are derived using the first 13 members of the RCP8.5 simulation averaged between 2015 and 2025 to include $\pm 5 \mathrm{yr}$ around 2020 (not all 20 RCP8.5 members were available at the time the first 13 feedback simulations started), leading to the global temperature target $\mathrm{T} 0,288.21 \mathrm{~K}$; the interhemispheric temperature target $\mathrm{T} 1,0.59 \mathrm{~K}$; and the equator-to-pole temperature target $\mathrm{T} 2,-6.01 \mathrm{~K}$ (Table 3). Very similar temperatures were derived when using all 20 ensemble members for the same period (not shown). For climatological comparisons we suggest comparing to a reference period 2010-30. Corresponding surface temperature values are listed in Table 3 (third row) and are also similar to the target temperatures used.

The geoengineering simulations start in 2020, where they branch from each of the 20 control simulations and are continued until 2099. The feedbackcontrol algorithm (see "Achieving temperature goals" section) is applied to each of the 20 members individually to reach the aboveprescribed target temperatures, resulting in slightly different injection amounts per location in each simulation (see Fig. 2). It should be noted that, while each of the feedback members is initialized in 2020 from ocean conditions that had already diverged between 2010 and 2020 in the control simulations, this is not sufficient to completely eliminate the memory of the ocean initial conditions in the Atlantic sector. All RCP8.5 and geoengineering ensemble members are prone to a more negative phase of the Atlantic multidecadal oscillation (AMO) (Trenberth and Shea 2006) around 2020 and then subsequently recover over the next 15-20 yr. The reason for this initial behavior has to be investigated in more detail, but 
TABLE 3. Ensemble mean surface temperature values for T0, TI, and T2 (K; see text). The target temperature chosen for the feedback-control mechanism to keep temperatures at 2020 conditions is shown in the first row. Values for recommended climatological comparisons between 2010 and $\mathbf{2 0 3 0}$ are shown in the second row, and results from the geoengineering simulations between 2020 and 2100 are shown in the third row. Values in parentheses describe the cross-ensemble standard deviation in each year averaged over the considered period.

\begin{tabular}{|lcccc|}
\hline Simulation & Average over (yr) & T0 (std dev) & TI (std dev) & T2 (std dev) \\
\hline RCP8.5 & $2015-25$ & $288.21(0.11)$ & $0.59(0.05)$ & $6.01(0.04)$ \\
\hline RCP8.5 & $2010-30$ & $288.25(0.11)$ & $0.62(0.05)$ & $6.00(0.04)$ \\
\hline Geoengineering & $2020-2100$ & $288.24(0.13)$ & $0.62(0.05)$ & $5.94(0.04)$ \\
\hline
\end{tabular}

should be taken into account when interpreting future changes in the Atlantic sector in these simulations.

\section{TECHNICAL DETAILS AND} MODEL OUTPUT. Model simulations were performed on the new Cheyenne high-performance computing platform built for the National Center for Atmospheric Research (NCAR) by Silicon Graphics International (SGI). A total of 22.8-million core hours were used to run a total of 2,227 years for this set of simulations. Comprehensive output has been produced to enable the analysis of various topics. Monthly output is available for the atmosphere, ocean, land, sea ice, and river runoff. Higher temporal resolution output has been produced for certain atmospheric variables,

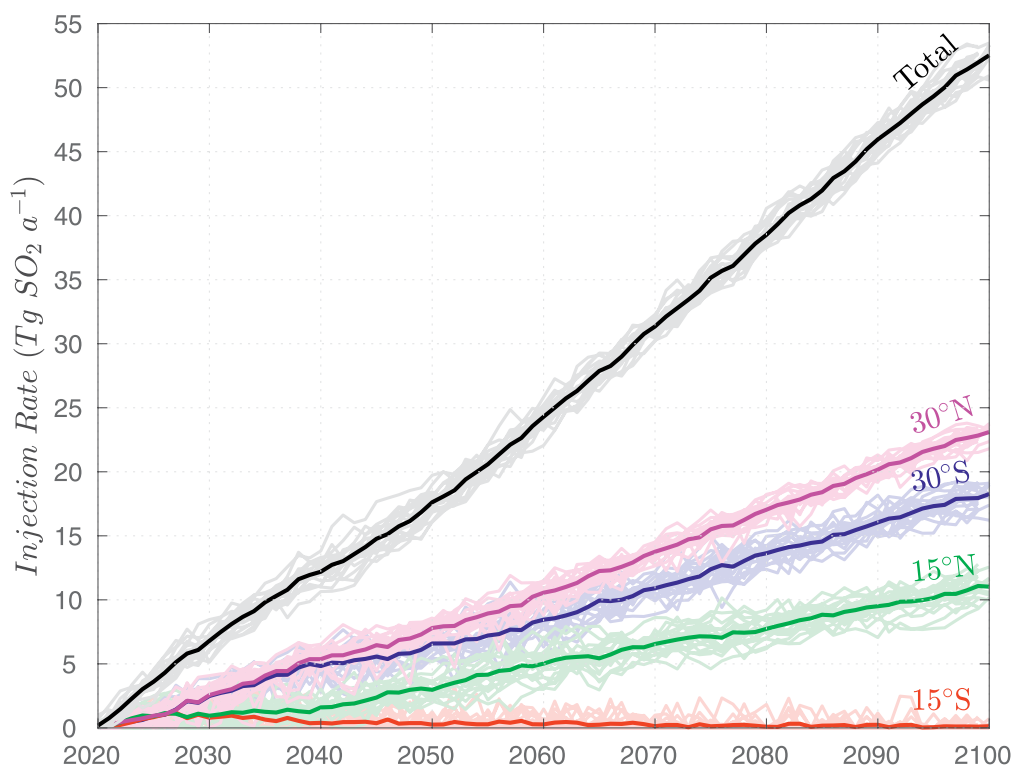

Fig. 2. Injection amount at each injection location ( $\left.\mathrm{Tg} \mathrm{SO}_{2} \mathrm{yr}^{-1}\right)$ at $15^{\circ} \mathrm{S}$ (red), $15^{\circ} \mathrm{N}$ (green), $30^{\circ} \mathrm{S}$ (blue), and $30^{\circ} \mathrm{N}$ (pink), as well as the total injection amount (black). Single ensemble members are shown in lighter colors, and the ensemble mean is in darker colors. including a 10-day instantaneous output of important stratospheric tracers and reaction rates of the most important stratospheric reactions; daily mean output of important climate, transport, and aerosol variables; 6-hourly mean output for investigating the diurnal cycle of temperature and wind on the full horizontal and vertical model grid; and other climate variables related to clouds, precipitation, and radiation. General diagnostics of the ensemble results for the atmosphere, land, ice, and ocean, as well as information on how to download the output from the NCAR Earth System Grid (ESG), are available at www.cesm.ucar.edu/projects /community-projects/GLENS/.

ACHIEVING TEMPERATURE GOALS. The basis for identifying four injection locations to maintain annually averaged temperature targets ( $\mathrm{T} 0$, $\mathrm{T} 1$, and $\mathrm{T} 2$, as defined above) is a set of 42 single-grid-

cell stratospheric injection experiments and combined injection experiments that identify the relationships between a single-grid-point stratospheric injection location and surface temperature changes (Tilmes et al. 2017; MacMartin et al. 2017). Both injection altitudes, at $\sim 1$ and $\sim 5 \mathrm{~km}$ above the tropopause, were tested within these experiments, and it was found that the higher injection location, as used for this ensemble, is more efficient in reducing surface temperatures for the same injection amount, but may result in different impacts (Tilmes et al. 2017). The required $\mathrm{SO}_{2}$ injection rates at each of the four injection locations needed to meet the temperature targets can be estimated prior to the start of the simulations from those early experiments. However, because of uncertainties and nonlinearities in the response of the system to $\mathrm{SO}_{2}$ injection, these initial estimates would lead to gradually growing deviations from the target values. To compensate 
for this, we use a feedback algorithm that annually adjusts the injection rates at each of the four locations in response to simulated deviations from the temperature targets based on a weighted contribution of deviations in both the preceding year and integrated through the simulation to that date [for details, see MacMartin et al. (2014) and Kravitz et al. (2016, 2017)]. This algorithm aims toward maintaining the target values of $\mathrm{T} 0$, T1, and $\mathrm{T} 2$ over time.

Global mean surface temperatures are successfully kept to the target temperature values (Fig. 1, top). The spread of the ensemble (cross-ensemble standard deviation in each year) is within the internal variability of RCP8.5 ensemble members between 2010 and 2030. The interhemispheric surface temperature (T1) goal is met but contains a slight positive bias (stronger warming in the Northern Hemisphere than the Southern Hemisphere) for the ensemble mean after 2040, resulting from the fact that the feedback algorithm never quite caught up with the continually increasing forcing. Despite this bias, values of T1 only change by a small amount such that the ensemble mean still lies within the ensemble spread of the reference period. Equator-to-pole temperature gradients are kept very close to 2010-30 conditions for roughly the first 20-30 yr. Thereafter, deviations from the control period increase with increasing injection amount. The initial estimate for injection rates was derived from a single earlier simulation with a different pole-to-equator and interhemispheric temperature gradient, using an earlier version of the land model, where injections were primarily at $30^{\circ} \mathrm{S}$ and $30^{\circ} \mathrm{N}$ (Kravitz et al. 2017). Over the initial decades of the simulation, the controller successfully converges to better manage the interhemispheric temperature gradient, leading to more $\mathrm{SO}_{2}$ injection at $15^{\circ} \mathrm{N}$ after 2040 , and hence a slightly different spatial pattern of response after 2040 compared with before. Since the algorithm successfully diagnoses the need to emphasis the interhemispheric gradient and cannot quite simultaneously manage all three degrees of freedom, the equator-to-pole temperature gradient goal was not perfectly reached. Nevertheless, by the end of the twenty-first century, the change in the equator-to- pole temperature gradient compared to the control in 2010-30 is still only about $15 \%$ of the change that occurs without geoengineering. The identification of these effects will lead to improvements in the feedback controller for future simulations.

The injection amount per location in the geoengineering simulations is shown in Fig. 2. Consistently across the ensemble members, about $80 \%$ of the injection amount is at $30^{\circ} \mathrm{N}$ and $30^{\circ} \mathrm{S}$, with most of the remaining injection at $15^{\circ} \mathrm{N}$ and very little at $15^{\circ} \mathrm{S}$. The total required injection amount by the end of the twenty-first century reached $52 \mathrm{Tg} \mathrm{SO}_{2}$ $\mathrm{yr}^{-1}$. This is about equivalent to an annual injection amount of 5 times the sulfur burden that reached the stratosphere after the eruption of Mount Pinatubo in 1991. As pointed out in earlier studies (Niemeier and Timmreck 2015; Kleinschmitt et al. 2017), the magnitude of the achieved radiative forcing reduction does not scale linearly with the $\mathrm{SO}_{2}$ injection amount; increasing $\mathrm{SO}_{2}$ injections result in relatively less radiative forcing reduction. However, as was also shown by Kravitz et al. (2017), in this setup, we derive a close to linear relationship between the injection amount and temperature change. The derived rate is approximately $1^{\circ}$ of cooling for $10 \mathrm{Tg} \mathrm{SO}_{2} \mathrm{yr}^{-1}$ for the combined injections at all four locations (Fig. 3). Details that lead to the linear behavior in the temperature response, including potential changes of aerosol properties with time, will be the subject of future studies.

\section{STRATOSPHERIC AEROSOL AND} TEMPERATURE RESPONSE. While the feedback control algorithm is designed to meet the three temperature targets, other changes in the climate stystem occur, for example, in stratospheric chemistry 
and dynamics (Richter et al. 2018; Tilmes et al. 2018). Stratospheric $\mathrm{SO}_{2}$ injections in the geoengineering simulation lead to the formation of sulfate aerosols with a maximum burden around the primary injection locations (Fig. 4). The larger injection amount in the Northern Hemisphere creates a higher vertical extension of the aerosol layer and larger mass burdens close to the injection locations as compared to the Southern Hemisphere. Resulting temperature changes in the tropical stratosphere (Fig. 5) are more comparable between hemispheres than the aerosol burden, because of the importance of both radiative and dynamical heating in response to geoengineering, as described in detail by Richter et al. (2017). Temperatures in the lower tropical stratosphere increase below the injection locations by around $5^{\circ} \mathrm{C}$ during $2040-$ 59 and around $10^{\circ} \mathrm{C}$ by the end of the twenty-first century, as compared to the control period. The increased cooling at later time periods in the upper stratosphere is the result of continuously increasing greenhouse gases as compared to RCP8.5 2010-30 conditions. The resulting changes in stratospheric processes can have important implications for the future evolution of stratospheric column ozone, which impacts the amount of ultraviolet radiation reaching the
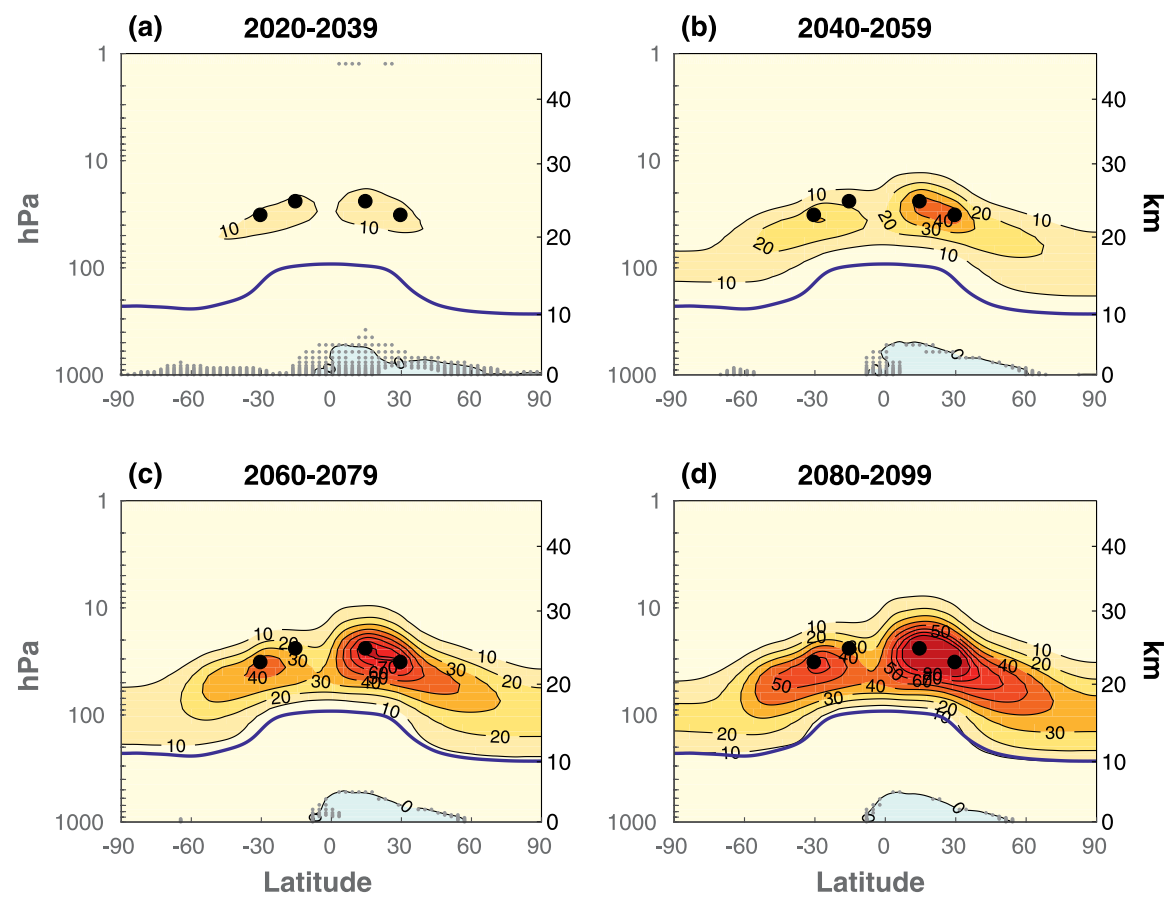

FIG. 4. Differences in the ensemble mean zonal and annual mean stratospheric sulfate mass mixing ratio between geoengineering averaged over different periods: (a) 2020-39, (b) 2040-59, (c) 2060-79, and (d) 2080-99 and RCP8.5 in 2010-30. Contours are in intervals of $10 \mu \mathrm{g} \mathrm{S}\left(\mathrm{kg}^{\mathrm{air}}\right)^{-1}$. Black circles depict the locations of $\mathrm{SO}_{2}$ injections.
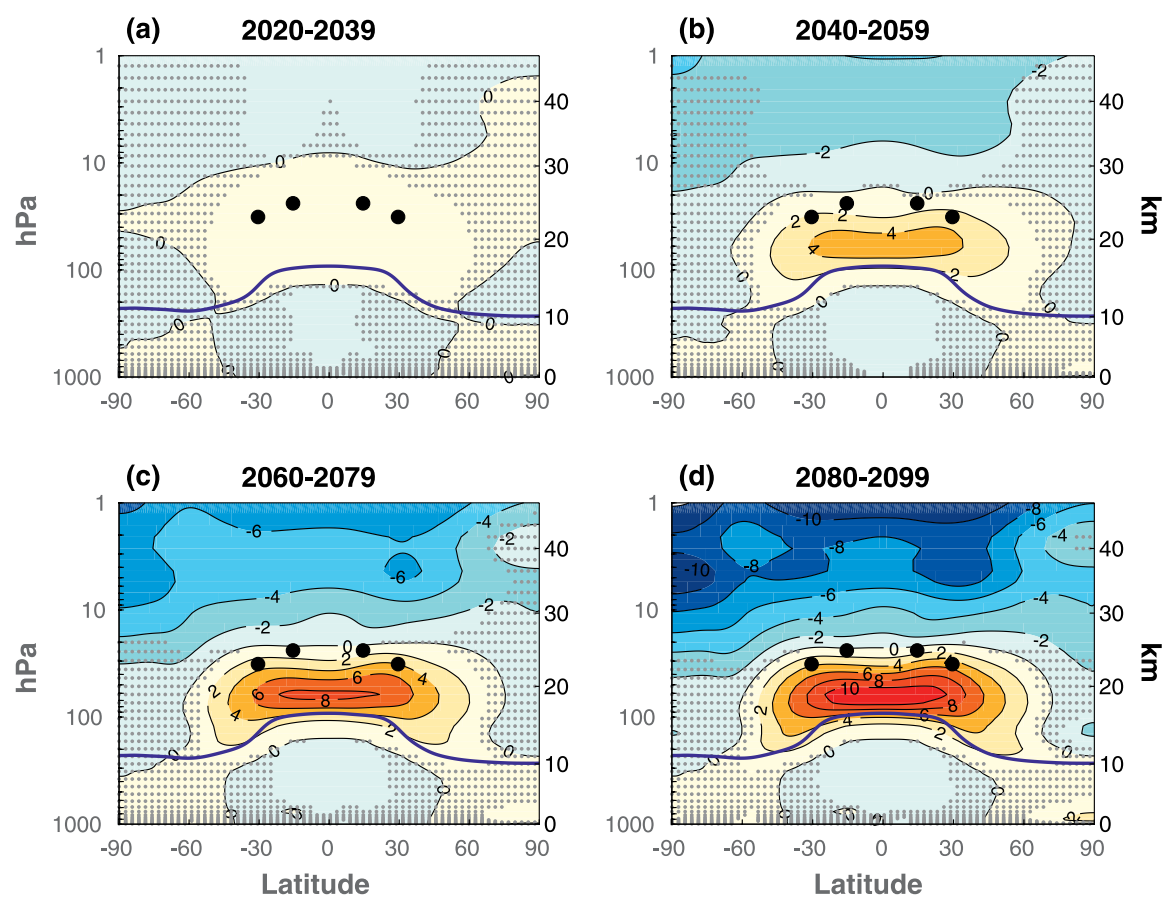

FIG. 5. Differences in the ensemble mean zonal and annual mean temperature between geoengineering averaged over different periods: (a) 2020-39, (b) 2040-59, (c) 2060-79, and (d) 2080-99 and RCP8.5 in 2010-30. Contours are in intervals of $2^{\circ} \mathrm{C}$. Black circles depict the locations of $\mathrm{SO}_{2}$ injections. 
Earth's surface, and can further impact surface climate. Additional changes in stratospheric dynamics include a potential modification of the QBO, which may also impact tropospheric winds and temperatures; these have yet to be investigated in detail. Increases in the stratospheric sulfate burden with increasing injection amounts of sulfur also are expected to feed back onto clouds, acid rain, and air quality.

\section{NEW OPPORTUNITIES TO STUDY REGIONAL CLIMATE IMPACTS. The appli-} cation of strategic stratospheric aerosol geoengineering has been demonstrated to result in much smaller global and regional temperature changes by the end of the century than the RCP8.5 simulation (Kravitz et al. 2017). This result is confirmed by the GLENS project (Fig. 6), showing regional temperature changes of the geoengineering ensemble mean below $\pm 1^{\circ} \mathrm{C}$ for most regions with maximum changes below $\pm 2^{\circ} \mathrm{C}$, compared to changes of up to $10^{\circ} \mathrm{C}$ for RCP8.5 between 2075 and 2095 and 2010 and 2030 . The relatively small changes in surface temperature in the geoengineering simulation are for the most part significantly different from zero ( $p$ value $<0.05$ ) using a two-sided $t$ test.

However, when it comes to identifying potential climatic impacts of the implementation of this kind of geoengineering scheme, it is not only necessary to identify robust mean changes, but also the range of possible outcomes (i.e., changes in extremes) that could arise as a result of the combined impact of both externally forced changes and internal variability. A detailed understanding of the magnitude of potential responses and an appreciation of the uncertainties due to sampling of short climate records on a regional scale will be required. While this is a first step, with a single model, the GLENS project will allow these issues to be addressed for the first time within the context of geoengineering. As an example, the histograms in Fig. 7 show the distribution of differences in 20-yr climatologies of near-surface air temperature between 2075 and 2095 under geoengineering and the RCP8.5 2010-30 reference period. The 20 ensemble members provide 400 such differences giving insights into the range of anomalies that may be experienced with a limited sample size. Figure 7 demonstrates that the sign, magnitude, and uncertainty in the temperature response are highly spatially variable, indicating regionally varying impacts of geoengineering that must be fully understood before such a scheme can be considered for real-world implementation. We only show surface temperature here, but given past experiments with the response to climate change (Deser et al. 2012a,b), we expect the quantities related to the hydrological cycle to exhibit greater variability. In addition, the large ensemble will allow for investigations into changes in extremes, such as heat waves and winter storms, which are of great relevance to society but cannot be investigated with individual realizations.

The high temporal resolution output of the provided meteorological fields further enables application of downscaling methods to explore regional and local impacts on society and the environment with additional perspective on the impacts of internal climate variability. For instance, cost estimations depending on $\mathrm{SO}_{2}$ injection amounts and other economical tradeoffs can be investigated. However, conclusions based on this project need to be viewed with care, keeping in mind that results are based on a single model. It (a) RCP8.5 (2075-2095) - RCP8.5 (2010-2030)

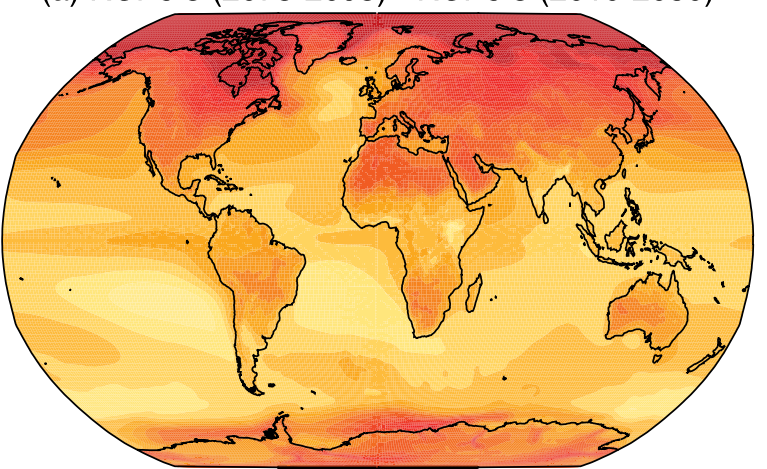

(b) GEOENGINEERING (2075-2095) - RCP8.5 (2010-2030)

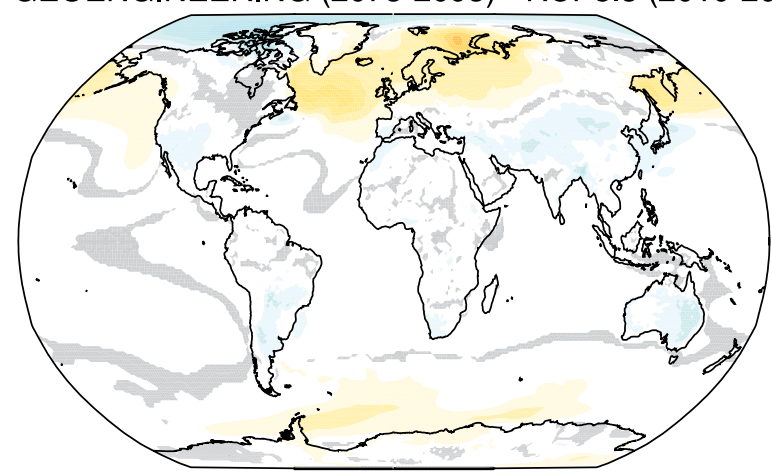

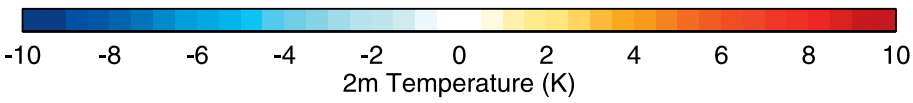

FIG. 6. Differences in the ensemble mean annual averaged 2-m temperature between (a) RCP8.5 in $2075-95$ minus RCP8.5 in 2010-30 and (b) between geoengineering in 2075-95 minus RCP8.5 in 2010-30. Gray areas indicate regions where the differences are not significantly different from zero ( $p$ value $<0.05$ ) using a two-sided $t$ test. 
is therefore important to discern whether regional changes are a result of robust physical mechanisms that would be expected to occur in the real world or whether they rely on the specifics of the model and therefore may be model dependent. Furthermore, future model development and updated components, for instance, the use of a more sophisticated aerosol model or increases in resolution, may significantly change the results.

Besides the atmospheric processes and regional climate change, land, sea ice, and ocean changes are important. For instance, changes induced by solar aerosol geoengineering on ocean currents and quantities including El Niño-Southern Oscillation and the Atlantic meridional overturning circulation (AMOC) have not been sufficiently studied in the past. Furthermore, detection and attribution studies have been performed on earlier multimodel results that did not include a strategic application of geoengineering, as presented in Bürger and Cubasch (2015). New insights into these research areas are expected based on this novel multiple-member ensemble dataset. Understanding the processes that lead to regional changes could motivate further exploration into how one could expand climate objectives, for instance, through different design choices, such as the locations or seasons of injection.

Finally, the chosen setup is not meant to suggest a reasonable application of geoengineering, because of the increasing risk of an abrupt termination of geoengineering and a rapid adjustment of temperatures back to uncontrolled conditions (Trisos et al. 2018). Responsible geoengineering should only be applied in addition to, and not as a substitute to, aggressive decarbonization to reduce the risks of climate change (e.g., Wigley 2006; Tilmes et al. 2016). Results from this study can be used to identify the injection amount that results in changes outside the observed range of historical variability, which is relevant for assessing reasonable limits of geoengineering.

\section{SUMMARY AND BROADER IMPLICA-} TIONS. The effects of stratospheric aerosol geoengineering on the Earth system and its implications for natural and human systems have to be carefully investigated before the method can be considered as a viable option for moderating global warming.

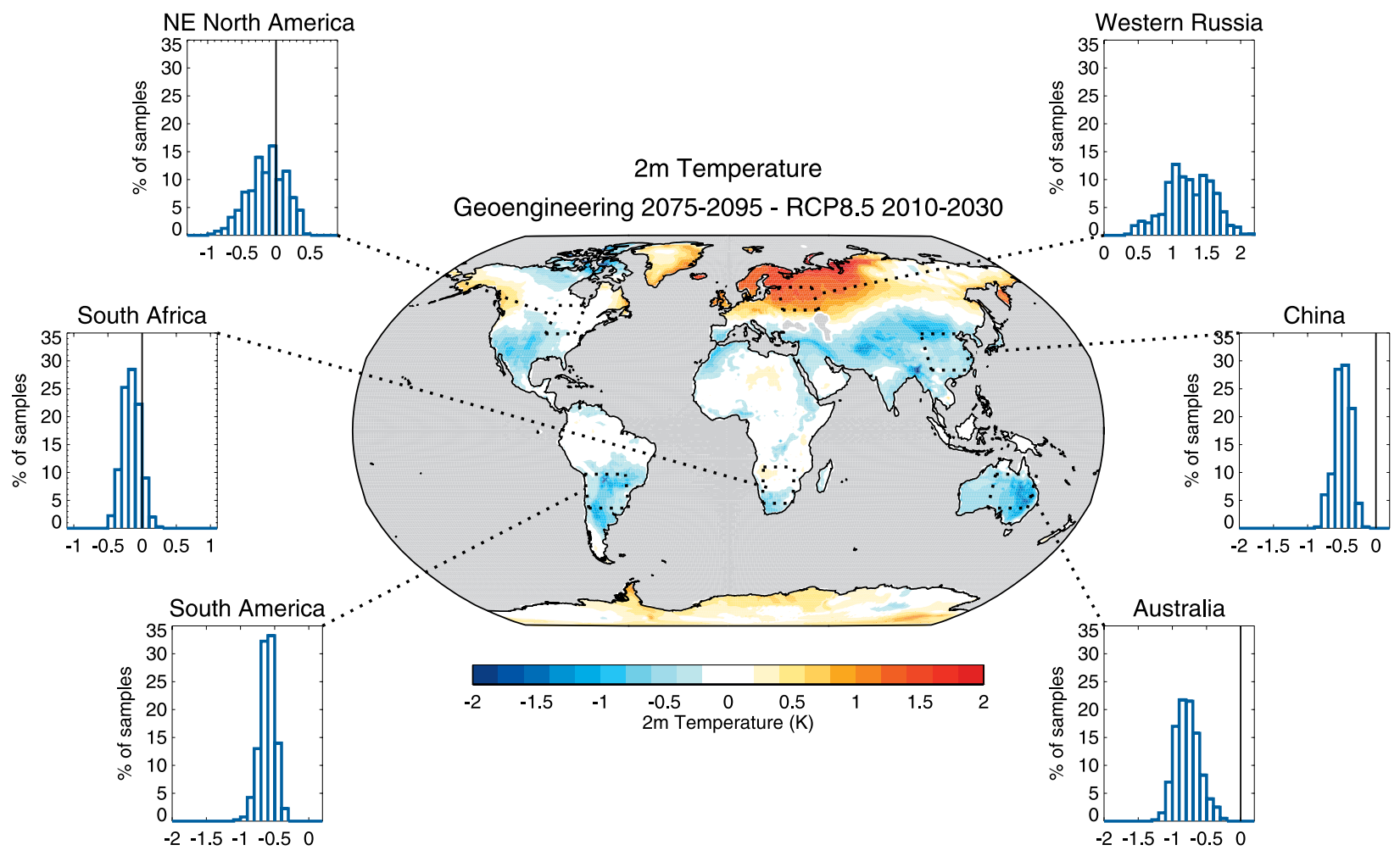

FIG. 7. Ensemble mean 2-m temperature change over land between 2075 and 2095 of the geoengineering simulations and between 2010 and 2030 of the RCP8.5 simulations (note that over land this is the same as in Fig. 6 b, but with a smaller contour interval). The surrounding histograms show the distribution of differences in 20 -yr climatologies of annual average 2-m temperature between 2075 and 2095 of the geoengineering simulations and between 2010 and 2030 of the RCP8.5 simulations. The 20 ensemble members give 400 possible differences to make up the distributions shown. 
The GLENS project presented here is a significant advancement over prior work in that it provides the community with a new and comprehensive dataset of strategically geoengineered state-of-theart climate simulations. We encourage the wider research community, including natural and social scientists, to use this dataset for evaluating and understanding the potential impacts of this geoengineering strategy. This project is an important step toward understanding the benefits, side effects, and risks associated with geoengineering, and supports the continued development of strategies that aim toward reducing risks and uncertainties of a potential future application, which is an essential first step in informing society and decision-makers.

ACKNOWLEDGMENTS. We thank Gary Strand and Ilana Stern, for publishing the model output on the NCAR Earth System Grid, and Alice Bertini, for offering software support in producing diagnostics for model results. The Pacific Northwest National Laboratory is operated for the U.S. Department of Energy by Battelle Memorial Institute under contract DE-AC05-76RL01830. Jean-Francois Lamarque's participation was supported in part by NSF Award 1243107. The CESM project is supported by the National Science Foundation and the Office of Science (BER) of the U.S. Department of Energy. The National Center for Atmospheric Research is funded by the National Science Foundation. This research was developed with funding from the Defense Advanced Research Projects Agency (DARPA). The views, opinions, and/or findings expressed are those of the authors and should not be interpreted as representing the official views or policies of the Department of Defense or the U.S. government. All simulations were carried out on the Cheyenne high-performance computing platform (www2.cisl.ucar.edu/user-support /acknowledging-ncarcisl) and are available to the community via the Earth System Grid (see information at www.cesm.ucar .edu/projects/community-projects/GLENS/).

\section{REFERENCES}

Aquila, V., C. I. Garfinkel, P. Newman, L. Oman, and D. Waugh, 2014: Modifications of the quasi-biennial oscillation by a geoengineering perturbation of the stratospheric aerosol layer. Geophys. Res. Lett., 41, 1738-1744, https://doi.org/10.1002/2013GL058818.

Bürger, G., and U. Cubasch, 2015: The detectability of climate engineering. J. Geophys. Res. Atmos., 120, 11 404-11 418, https://doi.org/10.1002/2015JD023954.

Crutzen, P. J., 2006: Albedo enhancements by stratospheric sulfur injections: A contribution to resolve a policy dilemma? Climatic Change, 77, 211-219, https://doi.org/10.1007/s10584-006-9101-y.
Danabasoglu, G., S. C. Bates, B. P. Briegleb, S. R. Jayne, M. Jochum, W. G. Large, S. Peacock, and S. G. Yeager, 2012: The CCSM4 ocean component. J. Climate, 25, 1361-1389, https://doi.org/10.1175 /JCLI-D-11-00091.1.

Deser, C., R. Knutti, S. Solomon, and A. S. Phillips, 2012a: Communication of the role of natural variability in future North American climate. Nat. Climate Change, 2, 775-779, https://doi.org/10.1038 /nclimate1562.

- A. Phillips, V. Bourdette, and H. Teng, 2012b: Uncertainty in climate change projections: The role of internal variability. Climate Dyn., 38, 527-546, https://doi.org/10.1007/s00382-010-0977-x.

Guenther, B., X. Jiang, C. L. Heald, T. Sakulyanontvittaya, T. Duhl, L. K. Emmons, and X. Wang, 2012: The Model of Emissions of Gases and Aerosols from Nature version 2.1 (MEGAN2.1): An extended and updated framework for modeling biogenic emissions. Geosci. Model Dev., 5, 1471-1492, https://doi .org/10.5194/gmd-5-1471-2012.

Haywood, J. M., A. Jones, N. Bellouin, and D. Stephenson, 2013: Asymmetric forcing from stratospheric aerosols impacts Sahelian rainfall. Nat. Climate Change, 3, 660-665, https://doi.org/10.1038/nclimate1857.

Holland, M., 2013: The great sea-ice dwindle. Nat. Geosci., 6, 10-11, https://doi.org/10.1038/ngeo1681.

Hurrell, J. W., and Coauthors, 2013: The Community Earth System Model: A framework for collaborative research. Bull. Amer. Meteor. Soc., 94, 1339-1360, https://doi.org/10.1175/BAMS-D-12-00121.1.

Jones, A. C., J. M. Haywood, N. Dunstone, K. Emanuel, M. K. Hawcroft, K. I. Hodges, and A. Jones, 2017: Impacts of hemispheric solar geoengineering on tropical cyclone frequency. Nat. Commun., 8, 1382, https://doi.org/10.1038/s41467-017-01606-0.

Kay, J. E., and Coauthors, 2015: The Community Earth System Model (CESM) large ensemble project: A community resource for studying climate change in the presence of internal climate variability. Bull. Amer. Meteor. Soc., 96, 1333-1349, https://doi.org /10.1175/BAMS-D-13-00255.1.

Kleinschmitt, C., O. Boucher, and U. Platt, 2017: Sensitivity of the radiative forcing by stratospheric sulfur geoengineering to the amount and strategy of the $\mathrm{SO}_{2}$ injection studied with the LMDZ-S3A model. Atmos. Chem. Phys., 18, 2769-2786, https://doi.org/10.5194 /acp-18-2769-2018.

Kravitz, B., and Coauthors, 2013: Climate model response from the Geoengineering Model Intercomparison Project (GeoMIP). J. Geophys. Res. Atmos., 118, 8320-8332, https://doi.org/10.1002/jgrd .50646 . 
, D. G. MacMartin, H. Wang, and P. J. Rasch, 2016: Geoengineering as a design problem. Earth Syst. Dyn., 7, 469-497, https://doi.org/10.5194/esd-7-469 -2016 .

,-- , M. J. Mills, J. H. Richter, S. Tilmes, J.-F. Lamarque, J. J. Tribbia, and F. Vitt, 2017: First simulations of designing stratospheric sulfate aerosol geoengineering to meet multiple simultaneous climate objectives. J. Geophys. Res. Atmos., 122, 12616-12634, https://doi.org/10.1002/2017JD027006.

Liu, X., and Coauthors, 2012: Toward a minimal representation of aerosols in climate models: Description and evaluation in the Community Atmosphere Model CAM5. Geosci. Model Dev., 5, 709-739, https:// doi.org/10.5194/gmd-5-709-2012.

MacMartin, D. G., B. Kravitz, D. W. Keith, and A. Jarvis, 2014: Dynamics of the coupled human-climate system resulting from closed-loop control of solar geoengineering. Climate Dyn., 43, 243-258, https:// doi.org/10.1007/s00382-013-1822-9.

— , — S. Tilmes, J. H. Richter, M. J. Mills, J.-F. Lamarque, J. J. Tribbia, and F. Vitt, 2017: The climate response to stratospheric aerosol geoengineering can be tailored using multiple injection locations. J. Geophys. Res. Atmos., 122, 12 574-12 590, https://doi .org/10.1002/2017JD026868.

Marsh, D. R., M. J. Mills, D. E. Kinnison, J.-F. Lamarque, N. Calvo, and L. M. Polvani, 2013: Climate change from 1850 to 2005 simulated in CESM1(WACCM). J. Climate, 26, 7372-7391, https://doi.org/10.1175 /JCLI-D-12-00558.1.

Mills, M. J., and Coauthors, 2016: Global volcanic aerosol properties derived from emissions, 1990-2014, using CESM1(WACCM). J. Geophys. Res. Atmos., 121, 2332-2348, https://doi.org/10.1002/2015JD024290.

- , and Coauthors, 2017: Radiative and chemical response to interactive stratospheric sulfate aerosols in fully coupled CESM1(WACCM). J. Geophys. Res. Atmos., 122, 13 061-13 078, https://doi .org/10.1002/2017JD027006.

Moore, J. C., and Coauthors, 2014: Arctic sea ice and atmospheric circulation under the GeoMIP G1 scenario. J. Geophys. Res., 119, 567-583, https://doi .org/10.1002/2013JD021060.

Niemeier, U., and C. Timmreck, 2015: What is the limit of climate engineering by stratospheric injection of $\mathrm{SO}_{2}$ ? Atmos. Chem. Phys., 15, 9129-9141, https://doi .org/10.5194/acp-15-9129-2015.

Oelson, K., and Coauthors, 2017: Technical description of version 4.5 of the Community Land Model (CLM). National Center for Atmospheric Research Tech. Rep. NCAR/TN-503+STR, 422 pp., https://doi .org/10.5065/D6RR1W7M.
Pitari, G., and Coauthors, 2014: Stratospheric ozone response to sulfate geoengineering: Results from the Geoengineering Model Intercomparison Project (GeoMIP). J. Geophys. Res. Atmos., 119, 2629-2653, https://doi.org/10.1002/2013JD020566.

Richter, J. H., S. Tilmes, M. J. Mills, J. J. Tribbia, B. Kravitz, D. G. MacMartin, F. Vitt, and J. F. Lamarque, 2017: Stratospheric dynamical response to $\mathrm{SO}_{2}$ injections. J. Geophys. Res. Atmos., 122, 12 557-12573, https://doi .org/10.1002/2017JD026912.

_- and Coauthors, 2018: Stratospheric response in the first geoengineering simulation meeting multiple surface climate objectives. J. Geophys. Res. Atmos., 123, 5762-5782, https://doi.org/10.1029/2018JD028285.

Schmidt, H., and Coauthors, 2012: Solar irradiance reduction to counteract radiative forcing from a quadrupling of $\mathrm{CO}_{2}$ : Climate responses simulated by four earth system models. Earth Syst. Dyn., 3, 63-78, https://doi.org/10.5194/esd-3-63-2012.

Tilmes, S., and Coauthors, 2013: The hydrological impact of geoengineering in the Geoengineering Model Intercomparison Project (GeoMIP). J. Geophys. Res. Atmos., 118, 11 036-11 058, https://doi.org/10.1002 /jgrd.50868.

— , B. M. Sanderson, and B. C. O’Neill, 2016: Climate impacts of geoengineering in a delayed mitigation scenario. Geophys. Res. Lett., 43, 8222-8229, https:// doi.org/10.1002/2016GL070122.

—, J. H. Richter, M. J. Mills, B. Kravitz, D. G. MacMartin, F. Vitt, J. J. Tribbia, and J.-F. Lamarque, 2017: Sensitivity of aerosol distribution and climate response to stratospheric $\mathrm{SO}_{2}$ injection locations. J. Geophys. Res. Atmos., 122, 12 591-12 615, https://doi .org/10.1002/2017JD026888.

—, and Coauthors, 2018: Effects of different stratospheric $\mathrm{SO}_{2}$ injection altitudes on stratospheric chemistry and dynamics. J. Geophys. Res. Atmos., 123 4654-4673, https://doi.org/10.1002/2017JD028146.

Trenberth, K. E., and D. J. Shea, 2006: Atlantic hurricanes and natural variability in 2005. Geophys. Res. Lett., 33, L12704, https://doi.org/10.1029 /2006GL026894.

Trisos, C. H., G. Amatulli, J. Gurevitch, A. Robock, L. Xia, and B. Zambri, 2018: Potentially dangerous consequences for biodiversity of solar geoengineering implementation and termination. Nat. Ecol. Evol., 2, 475-482, https://doi.org/10.1038/s41559-017 $-0431-0$

Wigley, T. M., 2006: A combined mitigation/geoengineering approach to climate stabilization. Science, 314, 452-454, https://doi.org/10.1126/science .1131728 . 